\title{
Sailing Vocational Colleges Reform and Research on Practical Teaching System of Marine Engineering Technology Specialty
}

\author{
Zhiqiang Zhao ${ }^{1, a}$ and WeiZhai ${ }^{2, b}$ \\ ${ }^{1}$ Binzhou Vocational College, Binzhou, Shandong Province 256600 \\ a103937818@qq.com, ${ }^{b} 154491773 @ q q . c o m$
}

Keywords: Vocational colleges; Marine engineering; Practical teaching; Reform measures

\begin{abstract}
In the context of global economic integration, China's maritime industry has been developed unceasingly, especially with the promulgation and implementation of the STCW Convention Manila Amendment and the new domestic navigation laws and regulations, to promote the development of maritime industry, but also make higher demands to the ship engineer. In this context, the author took the institutions of maritime education and practice teaching situation as the starting point, analyzing the necessity of the reform of engineering skills of the engineering system, and put forward the reform measures and method practice for teaching system, detailedly describing the practice of teaching reform measures for peer reference.
\end{abstract}

\section{Introduction}

Maritime class is a practical and applied subject, China's maritime vocational colleges have always stressed the cultivation of application skills and practical skills training. Under the background of modern science and technology, the ship is developing towards direction of large-scale, technical and specialization, especially with the improvement of international shipping science and technology, which puts forward higher requirements and challenges for maritime talents. The key to cultivating applied talents is to strengthen the practice teaching links. With the idea of broadening the practice of teaching reform and cultivating high-quality professionals, colleges and universities need to create a distinctive teaching reform system for the maritime higher vocational colleges to provide reference for the reform of practical teaching system of engineering technology specialty.

\section{Analysis of Status and Problem the Actual Teaching System}

The traditional management mode is popular in the practice teaching of maritime vocational colleges, which causes many problems and affect the quality and efficiency of practical teaching. In the immediate future, the specific situation is as follows:

The existence of "small and complete" situation in the construction of the laboratory, the communication between different majors is little, with duplication situation, greatly waste funds and resources, reduce equipment efficiency. Many of the institutions and schools set up time courses, little contact between each other, is not conducive to cultivating students' knowledge and comprehensive quality

Some institutions do not attach importance to practical teaching, affected by the "examination-oriented education" thinking; Students learn how to pass the theoretical examination, rather than how to practice.

The lack of contact between the content and the requirements of the experiment, the training teachers make single requirements for students, did not take differentiated teaching methods, so that the quality of the teaching staff is not clear, the impact of their work enthusiasm, the emergence of unstable teachers. Students can only be based on teachers to explain and standardize the training, the existence of this teaching model directly stifle students creativity and curiosity, is not conducive to cultivating students' innovative ability. 


\section{The Importance of Practical Teaching System Reform}

In the context of modern shipping, the market puts forward higher quality and technical requirements for marine engineers. In the Manila Amendment of the STCW Convention, ERM is placed in Part A as a mandatory requirement. In the functions of ship operations and personnel management, emphasis is placed on the ability to use task and knowledge to workload management and the rational use of resource management. Since the entry into force of the Manila Amendment on 1 January 2012, a five-year transition period has been in place and some of the engineers are still engaged in transitional training. Mandatory implementation makes the relevant institutions must carry out practice teaching system reform to meet the actual needs.

The training of engineering talents of marine engineering technology needs to fully consider the skills and practical factors, including students' knowledge structure, quality and practical ability to meet the relevant requirements; the introduction of "double certificate" training mode, that is, when students get professional diploma, at the same time, to obtain the three rounds of wheel competence certificate from Maritime Bureau of the organization of the theoretical examination and practical evaluation; Combination of work and study, focusing on cultivating practical ability to ensure consistence of the school learning knowledge and practice, to avoid the situation of disjoint; Staff positions set the appropriate curriculum system, assessment methods and evaluation methods, to train students professional ability.

In fact, the marine engineering technical major in the marine engineering colleges focus on training students practical ability, but the practice of training equipment and facilities cost is higher, with more consume, need to update some high-end equipment, need institutions to invest a lot of money. But subject to school funding and other factors, resulting in mismatching of training scale and student size, which can not meet the real needs. This requires to make a reasonable teaching plan to improve the teaching facilities and equipment using efficiency.

\section{Analysis of Reform Measures on the Practice Teaching System}

In view of the current situation and existing problems of the practice teaching of marine engineering technology, concrete reform and optimization measures are given.

Change the Traditional Teaching Concept, Do Connotation Management. Some teachers are influenced by the traditional concept, having the situation of paying attention to theory but light practice, the traditional teaching methods is applied in teaching process, not conducive to cultivating students' practical skills and comprehensive quality. The marine engineering in our school is based on the spirit of the work of the laboratory construction work, completely change the concept to build a leading group of laboratory construction, to strengthen the guidance of laboratory construction work and practice teaching reform, organically combining laboratory construction and practice teaching reform. At the same time, according to the actual situation and requirements to revise the practice of teaching plan, focusing on international conventions, substantially increase the energy-saving training content, practice teaching to reduce the verification of experimental projects, according to the actual situation to adjust the proportion of class hours to ensure that the total hours of practice teaching occupying at least $30 \%$ proportion. The specific course composition is as follows. 


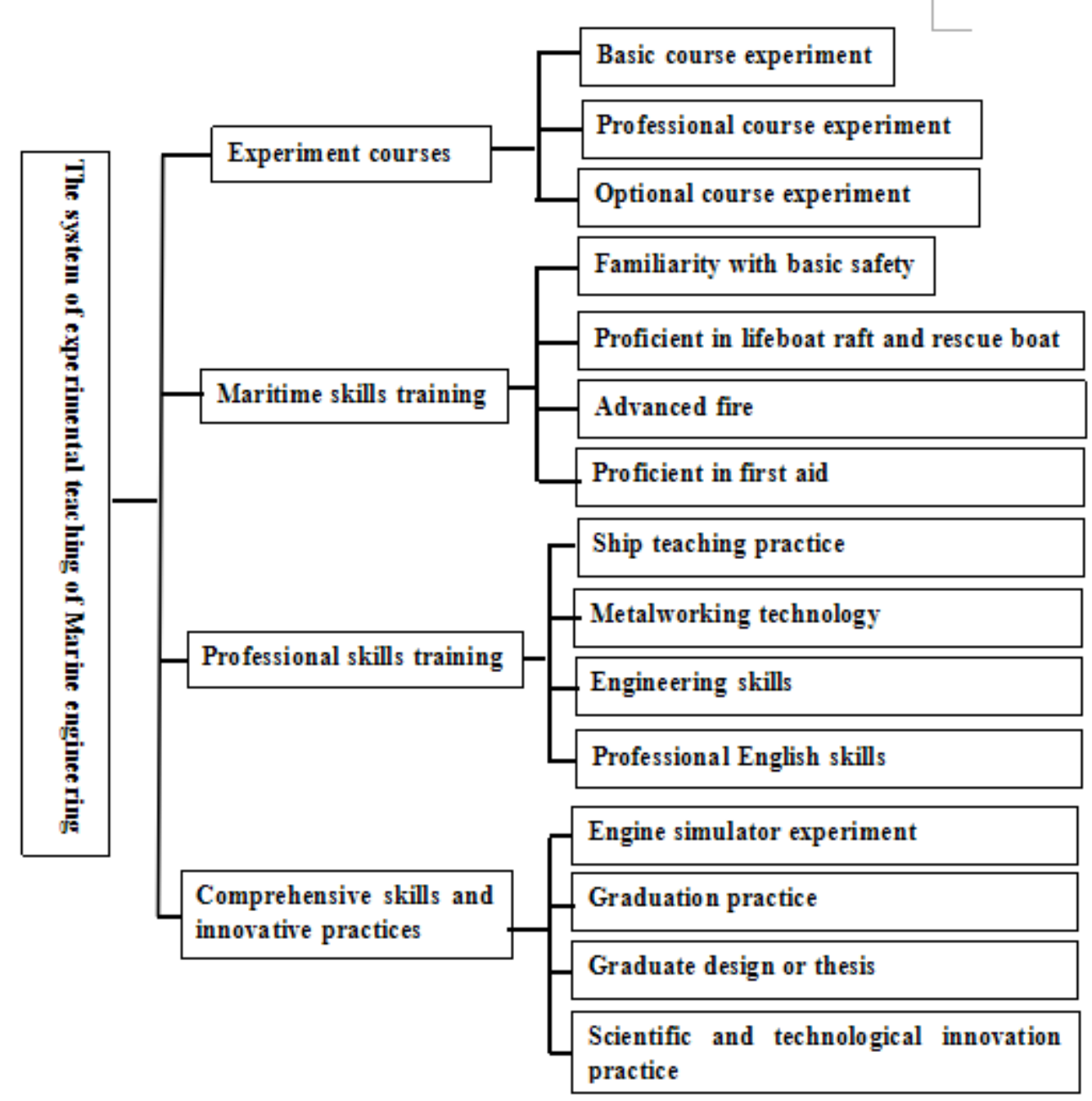

Figure. 1 the construction of practice course system

Marine engineering further improve the practice of teaching operation and management mechanism, strengthen the content management of specific measures are: improve the rules and regulations, so that the practice of teaching, equipment, safety and other management standardization, in the specified location to suspend laboratory management rules, safety practices, equipment operation procedures, etc.; do a good job in laboratory functions, projects, signs and other aspects of the layout, showing the laboratory culture environment, to create a professional atmosphere; enrich and improve the practice of teaching documents, practice syllabus, experimental training materials, experimental training reports, training supplies and equipment, complete maintenance records; in accordance with the school "crew education and training quality management system" requirements, know clearly the job responsibilities, and monitoring the implementation of quality teaching practice process.

Based on the Status Quo of Practical Teaching, Do A Good Job in the Construction of Teacher Morality. In the current practice teaching, influenced by the bad habits of society, some teachers are not responsible for their word, it is necessary to do a good job in the construction of the teacher morality.

Teacher education is an important aspect of strengthening the construction of teacher team, the school has assumed the important task of teacher education. First of all, at the level of laws and regulations, they should make teachers realize that the particularity of the teacher industry that the moral requirements for teachers is different from other areas, which is the mandatory state, never allowed to perform it discount. Second, in the professional level they need to make teachers understand the moral requirements is the high standards of the requirements on teachers, is the teacher industry "rules", since you are in the entry, so you must obey the regulations. Again, at the individual level, the improvement of the individual's moral level is a prerequisite for a society. The teacher should be the high standard of the moral of the 
times, but the teacher should not be kidnapped by morality, it is not right that many of the social rights of the teacher in life are devoid by occupational characteristics. At the same time, it is necessary to do a good job in the evaluation system

The construction of teachers will be included in the school teacher assessment content, and pay attention to the use of schools, teachers, teachers and students self-evaluation and mutual assessment and other means for assessment, the results of the examination system will ensure fairness.

In the faculty planning to join the division of morality construction, the school should held every year, through "teacher morality" selection activities to select excellent organizations and individuals and give rewards, and the results of the assessment and assessment be entered into the teacher's personal file, as the important reference of the future promotion, the annual assessment, training and evaluation for teachers.

In the school site, to add the division of the teacher supervision system, establish the system of taking school as the main body, while students, parents and society as the supplement, everyone participate in the supervision system to facilitate the timely understanding and master the information and dynamic, to correct the bad tendencies and problems for teachers [7].

To establish a comprehensive system of student evaluation, to improve relevant questionnaires and student complaints for the students to teachers' morality to form a student-based real-time evaluation system to stimulate students for the evaluation of the enthusiasm and initiative to strengthen teachers' attitudes to students, teaching rules and regulations, and so on.

\section{Practical and Virtual Combination, Innovate Practice Teaching Methods}

In the traditional teaching mode, the experimental teaching mode of marine engineering is usually carried out by means of physical equipment, but the investment in physical equipment training in the actual teaching process is large and the cost is high, and there is training for emergency operation and fault simulation restrictive, resulting in limited student practice, affecting the practical results.

In recent years, with the virtual technology and simulation technology advances and development, has developed a function of advanced marine simulator, marine electromechanical equipment and other virtual operating platform. In order to make the practice training of marine engineering professional more economical, efficient, safe and gradual, we can adopt the practice teaching mode of "combining reality and virtual", which is generally divided into three stages [8].

usually the first stage is using virtual reality platform as a supplement to the ship cabin virtual roaming, to help students familiar with their internal general equipment, systems, etc., to establish the concept of the initial cabin, while students can use the ship mechanical and electrical equipment virtual operating platform to carry out a simple virtual disassembly and other operations, with the engine simulator for semi-physical type of simulation operation practice training. And the training of the stage is not limited by the number of times and costs, students can fully understand and familiarize with the operation of various equipment, disassembly procedures, systematic training, lay the foundation for future physical training.

The second stage is a comprehensive training for the engine automation cabin. To help students familiar with the cabin of the power system and its equipment distribution, for the car, commissioning, refueling, refueling, and electricity, operation management and boiler operation and other specific engine room power equipment to carry out physical operation training, so that students can really get started in practicing. At this time, students through the first phase of the virtual platform exercises, familiar with mastery of operational skills, improve training results, at the same time, you can save the second stage of training time and training costs.

In the third stage, it will enter the real ship cabin for practical operation. When the students through the first stage and the second stage of the test, they can directly enter the real ship familiar with the actual flight of various cabin equipment for the actual operation. Through the three-stage system of learning, to help students establish a perfect "cabin" concept, effectively improve the students' practical ability and problem analysis ability. "Virtual and reality combination" of the teaching model replace the traditional physical operation will gradually turn into modern virtual equipment operation and virtual machine practice mode, a single, boring automated cabin practice get into a higher level of the marine system 
teaching development. Therefore, the combination of "virtual and practical" teaching model can effectively improve students' ability to find problems, analyze problems and solve problems, cultivate students' innovative consciousness and innovation ability, shorten the run-in period of students' competent positions and become senior engineer growth cycle [11].

The introduction of micro-class teaching method. The micro-course is a new way of teaching. It is characterized by refined content, short and pithy, able to accurately grasp the needs of students, to provide students with high quality and efficient teaching, but also to guide the development of students thinking, and thus promote students learning ability and the growth of thinking ability, in the current teaching application of micro-class is worth trying. Our school has recently carried out curriculum reform to introduce micro-class teaching method. (1) Select the appropriate recording content. Pre-recorded a knowledge point, and then sent to the students, so do not need to repeat the same class content again and again, students can according to need, repeatedly watch less understood knowledge, saving time, and focus on the lesson of creative guidance and communication; (2) pay attention to student feedback. In the $3 \mathrm{dmax}$ lesson, all the knowledge points will be recorded with video capture software to 5 minutes of knowledge points to explain and operate the demo, the video is uploaded to school public platform, the students can leave a message, make an interaction, or teacher Q \& A; (3) exercise students thinking ability. Teachers in the micro-class teaching need to focus on strengthening the inspiration for students thinking. Teachers can also actively use the micro-class for experimental teaching, because some school resources are limited, it can't achieve that everyone is personally educated in the experiment, the teacher can record the complete experimental process, so that students can observe in the spare time, make a guidance for students thinking to achieve the development of thinking ability.

\section{Conclusion}

In summary, the marine engineering technology of the marine engineering colleges should be guided by the Ministry of Education and navigation regulations, the reform to build the engineer positions as the core of the practice of teaching has made some achievements so far. Increase the construction of practical teaching base and the construction of teachers, through innovative practice teaching methods to promote the utilization of equipment and enhance the actual integration of the practice of teaching projects, effectively training students' vocational skills. In addition, the maritime education practitioners should attach great importance to these issues, improve the quality of practical teaching and transport more high-quality technical personnel for China's shipping industry.

\section{References}

[1] Gao Xiaorui. Marine engineering "hydraulic drive and control" course teaching reform [J]. Technology Information. 2017 (24): 23.

[2] He Yuhai, Chen Yongzhi, Yang Zhiyong, Chen Jinsong. Study and practice of cultivating model of innovative talents in marine engineering discipline based on collaborative innovation and scientific and technological integration [J]. Journal of Higher Education Research and Practice. 2016(02):87.

[3] Wang Jun. Marine engineering course teaching system reform [J]. Education and Teaching Forum .2014 (37): 92.

[4] Wang Haiyan. Comparative study of marine engineering in China and Denmark [J]. Journal of Maritime Education. 2014 (03): 72.

[5] Wang Yongzhou. System engineering theory of marine engineering professional practice teaching [J]. Bohai Sea Engineering. 2017 (06): 73.

[6] Yu Hongliang. Study on the reform of practical teaching of marine engineering specialty evaluation [J]. Journal of Experimental Science and Technology. 2016 (03): 34. 
[7] Zhang Yuewen, Zhao Junhao. Study on the practice of ship recognition practice of marine engineering based on ship and shore integration [J]. Journal of Maritime Education. 2015 (01): 87.

[8] Wen Huaibing, Yang Xinglin, Liu Wei, Chen Ning, Feng Guozeng, Kong Xianglei. Study on innovative talents training mode and training platform of marine engineering specialty $[\mathrm{J}]$. Bohai Engineering. 2014 (01): 101-102.

[9] Gao Lan, Yin Qizhi, Gao Guozhang, Chen Yongzhi, Qian Zuogin. Study and practice on curriculum system reform of marine engineering specialty in new situation [J]. Journal of Transportation Enterprises. 2016 (02): 78.

Qian Zuoqin, Yang Zhiyong, Zhang Ben. Implementation and guarantee of the training program for excellence engineers in marine engineering [J]. Journal of Transportation Enterprises Management. 2015 (06): 92.

Zhao Jie, Li Chunhua, Xu Yimin, Cui Chongxin, Jiang Zhicheng. Study and exploration of practical teaching system of automation specialty [J]. Laboratory Research and Exploration. 2017 (07): 45.

Wang Qi, Shen Suhai, Shi Zhubin. Construction and thinking of shared teaching resource pool for engineering specialty in higher vocational colleges [J]. Vocational and Technical Education. 2016 (14): 81. 